\title{
Erratum to: Serotype distribution in pneumococcal acute otitis media with ruptured tympanic membrane or sepsis in Germany
}

M. van der Linden $\cdot$ R. R. Reinert

Published online: 16 July 2010

(C) Springer-Verlag 2010

Erratum to: Eur J Clin Microbiol Infect Dis

DOI: 10.1007/s10096-010-0945-8

The author's would like to point out that the incorrect figure 1 was published in the original article. Please see below for the correct figure 1 .

\section{Serotype Distribution for Pneumococcal OM Gemany} All Ages and $<5$ years

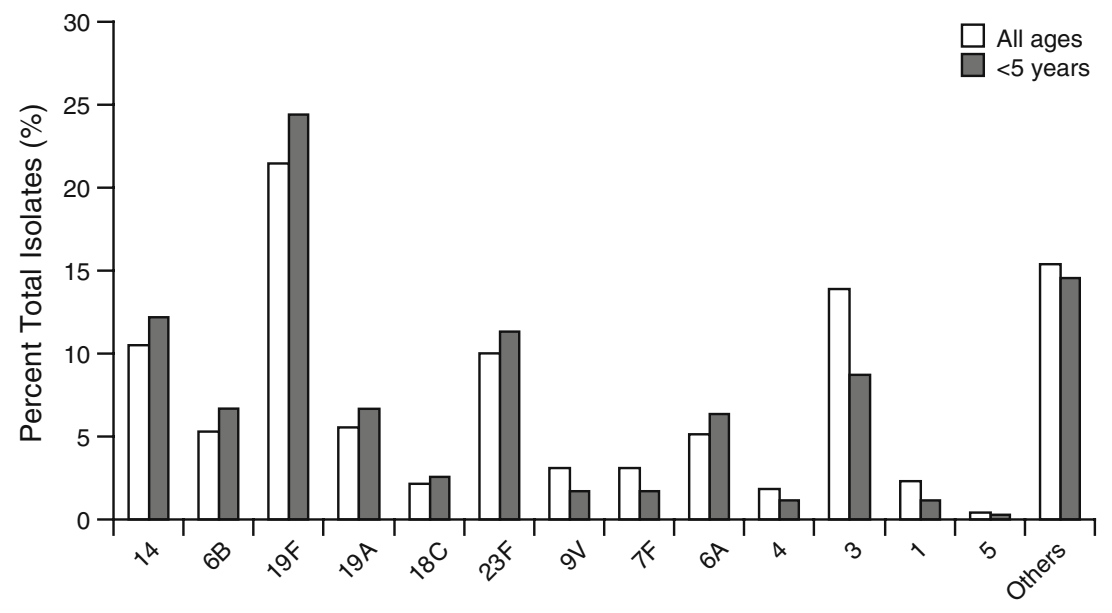

The online version of the original article can be found at http://dx.doi. org/10.1007/s10096-010-0945-8.

M. van der Linden $(\bowtie)$

Department of Medical Microbiology, National Reference Centre for Streptococci, University Hospital RWTH Aachen,

Pauwelsstr. 30,

52074 Aachen, Germany

e-mail: mlinden@ukaachen.de

R. R. Reinert

Pfizer Inc. (formerly Wyeth Vaccines Research), Paris La Défense,

Paris, France 